\title{
The effectiveness of rotavirus vaccine in preventing acute gastroenteritis during rotavirus seasons among Polish children
}

\author{
Dorota Mrozek-Budzyn, Agnieszka Kieltyka, Renata Majewska, Malgorzata Augustyniak
}

Department of Epidemiology, Chair of Epidemiology and Preventive Medicine, Jagiellonian University Medical College, Krakow, Poland

Submitted: 7 July 2014

Accepted: 30 September 2014

Arch Med Sci 2016; 12, 3: 614-620

DOI: 10.5114 /aoms.2016.59935

Copyright (c) 2016 Termedia \& Banach

\section{Abstract}

Introduction: Rotavirus is the main etiological cause of intestinal infections in children. Voluntary rotavirus vaccines were included in the Polish vaccination schedule in 2007. The aim of this study was to assess the effectiveness of a completed rotavirus vaccination course in preventing acute gastroenteritis in Polish infants during their first five years of life.

Material and methods: This was a retrospective cohort study conducted in Lesser Poland (Malopolska Province). The sample population included a group of 303 children who received the completed rotavirus vaccination course and 303 children not vaccinated against rotavirus. The date of the child's acute gastroenteritis diagnosis and his or her vaccination history were extracted from the physicians' records. Each kind of diagnosed acute gastroenteritis during winter-spring rotavirus seasons was treated as the endpoint. The relative risk of having gastrointestinal infection was assessed using the hazard ratio from the Cox proportional hazards regression model. Results: In the examined group, 96 (15.8\%) children had winter-spring gastrointestinal infections. In the non-vaccinated children, the cumulative incidence of these infections in the first 5 years of life was $20.8 \%$, whereas in the children vaccinated with Rotarix it was only $10.9 \%$. Those who were vaccinated with Rotarix had a $44 \%$ reduction in the risk of a winter-spring acute gastroenteritis infection compared to those not vaccinated with Rotarix $(p=0.005)$. Birth weight less than $2500 \mathrm{~g}$ increased the risk of the infection twofold and also reached statistical significance $(p=0.044)$.

Conclusions: The results showed that Rotarix is effective in preventing acute gastroenteritis in Polish children during rotavirus seasons.

Key words: rotavirus vaccine, effectiveness, acute gastroenteritis.

\section{Introduction}

Rotavirus is the leading cause of severe pediatric gastroenteritis [1, 2]. The rotavirus vaccines (Rotarix and RotaTeq) were licensed and recommended for routine immunization in the European Union in 2006 [3]. The results of a pre-licensure trial suggest very high efficacy of both vaccines in preventing rotavirus gastroenteritis [4-7]. Nevertheless, the effectiveness of vaccination in practice differs from the efficacy observed in the ideal conditions of a clinical trial. Furthermore, the vaccines are indicated for the prevention of rotavirus gastroenteritis caused by certain virus

\author{
Corresponding author: \\ Dorota Mrozek-Budzyn \\ Department of Epidemiology \\ Chair of Epidemiology \\ and Preventive Medicine \\ Jagiellonian University \\ Medical College \\ 7a Kopernika St \\ 31-034 Krakow, Poland \\ Phone: +48124231003 \\ Fax: +48 124228795 \\ E-mail: dorotamrozek@tlen.pl
}


serotypes which are not distributed in the same range in different populations [8, 9]. Apart from the host factors, it could be an important reason for higher vaccine efficacy in developed countries compared with developing ones. The efficacy of both vaccines has ranged from $80 \%$ to $98 \%$ in industrialized countries and in Latin America, but in countries such as Kenya and Malawi in Africa and Bangladesh and Vietnam in Asia the efficacy was lower, ranging from $51 \%$ to $64 \%$ [10-15].

Before introduction of the rotavirus vaccine in 2007, rotavirus was a leading etiological agent of severe gastroenteritis in young children in Poland [16]. Incidence rates of viral gastroenteritis in the entire population in 2007-2012 were estimated between 57.6 and 116.6 per 100 000, while in children up to the $2^{\text {nd }}$ year of life these were between 1371.7 and 2288.4 per 100 000. Both in the entire population and in the children up to the age of 2 , rates presented an increasing trend. A similar trend was observed in the incidence of rotavirus gastroenteritis in the entire population, with values from 39.9 to 79.9 per 100000 [17-19].

We use both rotavirus vaccines (Rotarix and RotaTeq) simultaneously, according to the national immunization program, as a voluntary option which requires that parents spend extra money for their children's vaccination, so not many infants have been vaccinated yet (annually less than 20\% of the population up to the $12^{\text {th }}$ month of life). The two vaccines differ greatly in their conception and expression of rotavirus strains. Rotarix is a human monovalent vaccine and RotaTeq is a bovine-human pentavalent vaccine $[20,21]$. Furthermore, there are no reliable data with respect to the dominant rotavirus serotype in our population. This situation is a reason for raising a question about the effectiveness of rotavirus vaccination in Poland.

The aim of the study was to assess the effectiveness of a completed rotavirus vaccination course in preventing acute gastroenteritis during rotavirus seasons in Polish infants during the first 5 years of their life.

\section{Material and methods}

This was a retrospective cohort study.

\section{Study population}

Subjects were identified using physicians' records in the Lesser Poland (Malopolska) Province in Poland. All children who met the inclusion criteria in randomly selected general practices and whose parent signed the consent were included in the study cohort. There was not a sufficient number of infants vaccinated with RotaTeq to achieve any conclusive results with respect to this vaccine, so we limited our analysis to the effectiveness of
Rotarix. The sample population of this study included 2 cohorts, 303 children in each. One group received a complete Rotarix (manufactured by GlaxoSmithKline Biologicals S.A., Rue de l'Institut 89, B-1330 Rixensart, Belgium) course -2 doses concurrently with other vaccines according to the immunization schedule. The vaccine was administered to infants aged 6 weeks up to 24 weeks of life. The minimal interval between the first and the second dose of Rotarix was 4 weeks. The control group received other vaccines, but not the rotavirus vaccine, through the period 2007-2012. The infants in the non-vaccinated cohort derived from the same physicians' practice as the vaccinated group. Infants vaccinated with long delays or those who did not obtain 2 doses of Rotarix vaccine were excluded from the study population.

The study was approved by the Jagiellonian University Ethical Committee (Krakow, Poland).

\section{Gastroenteritis diagnosis and vaccination history}

The date of the child's acute gastroenteritis diagnosis and his or her vaccination history were extracted directly from the physician's records. The definition of acute gastroenteritis was based on physician's diagnosis, ICD-10 code: A02.0, A04, $A 05, A 08, A 09$. In our cohort there were not many cases with the determined etiology of acute gastroenteritis. We counted as the endpoint each kind of diagnosed acute gastroenteritis (with determined and undetermined etiology) if it occurred during winter-spring rotavirus seasons (December to May in 2007-2012). The choice of rotavirus season was based on the proportion of reported cases of rotavirus gastroenteritis in the total reported cases of gastroenteritis (A02.0, A04, A05, A08, A09) in the entire population, calculated from biweekly reports on cases of infectious diseases and poisonings in Poland published by the National Institute of Public Health - National Institute of Hygiene [22]. In the studied period an increased proportion (about 40\%) was observed in the winter-spring season (December to May) compared to the summer-autumn season (June to November) (about 20\%). Only about 30\% of all viral gastroenteritis (A08) cases occurred outside the rotavirus season in Poland. The same proportion was observed according to rotavirus infections. Taking into account all acute gastroenteritis (A02.0, A04, $A 05, A 08, A 09)$ cases, about $45 \%$ of them occurred outside the rotavirus season [22].

Some additional information about the medical condition of infants that could potentially influence vaccine effectiveness and the risk of gastrointestinal infection, such as gestational age, Apgar score, birth weight and length, neonatal infections, congenital malformations and communi- 
cable diseases in infancy, were also extracted from the medical records.

\section{Questionnaire for the parents of infants}

Mothers were interviewed by trained nurses using a standardized questionnaire. Questions included information about prenatal and postnatal development, birth order, feeding mode, family size and parents' education.

\section{Statistical analysis}

Episodes of acute gastroenteritis were included to analyze whether they occurred in the vaccinated infants at least 14 days after receiving the complete vaccination course (second dose of Rotarix). This length of time is essential to reach a sufficient immunological response to such a vaccine. In controls, gastrointestinal infections were included in the analysis if they took place after 122 days of life (108 days, as the median of the second dose administration in the vaccinated group +14 days for the immunological response).

The relative risk of having a gastrointestinal infection during the first 5 years of life was assessed using the hazard ratio (HR) with $95 \%$ confidence intervals $(\mathrm{Cl})$ from the Cox proportional hazards regression model. Variables such as age, parental education (university vs. secondary or lower), place of living, breastfeeding $(<6$ months vs. $\geq 6$ months), birth weight ( $<2500 \mathrm{~g}$ ) and presence of other children in the family were taken into consideration as potential confounders. Vaccine effectiveness was calculated as: $(1-H R) \times 100$. Analyses were performed using STATA 12.1 software.

\section{Results}

The study population consisted of 303 children vaccinated with Rotarix and 303 controls, mean age $2.7 \pm 1.2$ years (range from 3 months to 6 years), $50.8 \%$ boys and $49.2 \%$ girls (Table I). Mean age differed by 2 months between the non-vaccinated and Rotarix vaccinated group. Parents of the children vaccinated against rotaviruses were better educated than parents of the non-vaccinated ones: the percentage of mothers with a university degree was $56.3 \%$ vs. $40.0 \%$, fathers: $33.4 \%$ vs. $22.3 \%$ respectively. This fact represented a statistically significant difference. Children from the vaccinated group less often had siblings ( $53.0 \%$ vs. $64.0 \%, p<0.007)$ and more often lived in a big city ( $9.6 \%$ vs. $2.0 \%, p<0.001)$. The examined groups did not differ significantly either in birth weight or in percentage of breastfed children.

Among the examined group, 95 (15.7\%) children suffered from winter-spring gastrointestinal infections. In the non-vaccinated children, the cu- mulative incidence in the first five years of life was $20.5 \%$, whereas in those vaccinated with Rotarix it was only $10.9 \%(p=0.001)$. Figure 1 presents Kaplan-Meier curves of acute gastroenteritis incidence during the 5-year period in the vaccinated and non-vaccinated group. The Rotarix vaccinated children had significantly better survival (log-rank test, $p=0.0053$ ).

The univariate Cox model-based survival analysis showed that among considered factors, only Rotarix vaccine and low birth weight were significant predictors of gastrointestinal infection. Rotarix vaccine had a significant protective effect. Among the children vaccinated with Rotarix, the risk of developing acute gastroenteritis in the winter-spring season during their first 5 years of life was lower by $44 \%$ compared to the non-vaccinated population $(p=0.005)$. Birth weight less than $2500 \mathrm{~g}$ increased the risk of infection twofold and also reached statistical significance $(p=0.047)$. Other variables defined as potential confounders did not influence vaccine effectiveness. The two variables birth weight and vaccination with Rotarix were taken into the multivariate model. After this adjustment, the proportional hazard ratio for vaccination with Rotarix and low birth weight did not change substantially and remained statistically significant (Table II). A similar analysis was conducted separately for the first 1, 2, 3 and 4 years of life (Table III). The effect of Rotarix was significant except for the first year of life, which is probably a consequence of the small number of cases and the short period of follow-up. From the second year of life the vaccine effectiveness became significant.

\section{Discussion}

Our findings demonstrate the influence of an effective rotavirus vaccine in preventing acute gastroenteritis among Polish children. In our study cohort the effectiveness of a full 2-dose Rotarix course over five winter-spring rotavirus seasons in children up to the $2^{\text {nd }}, 3^{\text {rd }}, 4^{\text {th }}$ and $5^{\text {th }}$ year of life was high and ranged from 42.5 to 45.5. During non-rotavirus seasons the vaccine demonstrated some effectiveness against all-cause gastroenteritis, although it was not significant. This vaccine's effectiveness in non-rotavirus seasons could be due to rotavirus cases that occurred outside the winter seasons or perhaps because of the cross-protection against other enteric viruses, although the mechanism of this effect is unknown [23].

The assumption of the winter-spring rotavirus season from December to May is consistent with the results of previous studies conducted in countries from a similar climate zone [24] and Polish surveillance data related to control of rotavirus infections [22]. High rotavirus vaccination cover- 
Table I. Characteristics of participants stratified by children vaccinated and not vaccinated against rotavirus

\begin{tabular}{|c|c|c|c|c|c|c|}
\hline \multirow[t]{3}{*}{ Parameter } & & \multicolumn{4}{|c|}{ Number and percentage of children } & \multirow[t]{3}{*}{$P$-value } \\
\hline & & \multicolumn{2}{|c|}{$\begin{array}{l}\text { Non-vaccinated } \\
\quad(N=303)\end{array}$} & \multicolumn{2}{|c|}{$\begin{array}{l}\text { Vaccinated with } \\
\text { Rotarix }(N=303)\end{array}$} & \\
\hline & & $N$ & $\%$ & $N$ & $\%$ & \\
\hline \multirow[t]{2}{*}{ Gender } & Male & 154 & 50.8 & 154 & 50.8 & \multirow[t]{2}{*}{ NS } \\
\hline & Female & 149 & 49.2 & 149 & 49.2 & \\
\hline \multirow[t]{3}{*}{ Living place } & Rural area & 179 & 59.1 & 169 & 55.8 & \multirow[t]{3}{*}{$<0.001$} \\
\hline & Small city & 118 & 38.9 & 105 & 34.6 & \\
\hline & Big city (> 100000 inhabitants) & 6 & 2.0 & 29 & 9.6 & \\
\hline \multirow[t]{2}{*}{ Pregnancy } & Single & 294 & 97.0 & 301 & 99.3 & \multirow[t]{2}{*}{0.063} \\
\hline & Multiple & 9 & 3.0 & 2 & 0.7 & \\
\hline \multirow{4}{*}{$\begin{array}{l}\text { Mother's } \\
\text { education }\end{array}$} & Elementary & 9 & 3.0 & 0 & - & \multirow[t]{4}{*}{$<0.001$} \\
\hline & Vocational & 50 & 16.6 & 29 & 9.7 & \\
\hline & Higher & 122 & 40.4 & 102 & 34.0 & \\
\hline & University & 121 & 40.0 & 169 & 56.3 & \\
\hline \multirow{4}{*}{$\begin{array}{l}\text { Father's } \\
\text { education }\end{array}$} & Elementary & 12 & 4.0 & 9 & 3.0 & \multirow[t]{4}{*}{0.002} \\
\hline & Vocational & 107 & 35.7 & 64 & 21.4 & \\
\hline & Higher & 114 & 38.0 & 126 & 42.2 & \\
\hline & University & 67 & 22.3 & 100 & 33.4 & \\
\hline \multicolumn{2}{|c|}{ Other children in the family } & 194 & 64.0 & 160 & 53.0 & 0.007 \\
\hline \multirow{4}{*}{$\begin{array}{l}\text { Number of } \\
\text { children } \\
\text { living in the } \\
\text { same flat }\end{array}$} & 1 & 136 & 69.4 & 129 & 80.1 & \multirow[t]{4}{*}{0.022} \\
\hline & 2 & 39 & 19.9 & 26 & 16.2 & \\
\hline & 3 & 15 & 7.6 & 6 & 3.7 & \\
\hline & 4 or more & 6 & 3.1 & 0 & 0.0 & \\
\hline \multicolumn{2}{|c|}{ Siblings vaccinated against rotaviruses } & 8 & 3.8 & 49 & 31.8 & $<0.001$ \\
\hline Birth weight & $<2500 \mathrm{~g}$ & 14 & 4.6 & 10 & 3.4 & NS \\
\hline \multirow[t]{3}{*}{$\begin{array}{l}\text { Breast } \\
\text { feeding }\end{array}$} & No & 23 & 7.9 & 23 & 7.8 & \multirow[t]{3}{*}{ NS } \\
\hline & $\leq 6$ months & 109 & 30.8 & 91 & 31.1 & \\
\hline & $>6$ months & 160 & 61.3 & 179 & 61.1 & \\
\hline \multicolumn{2}{|c|}{ Age, mean \pm SD [years] } & \multicolumn{2}{|c|}{$2.86 \pm 1.22$} & \multicolumn{2}{|c|}{$2.63 \pm 1.09$} & 0.010 \\
\hline
\end{tabular}

age in infants is likely to postpone and shorten the rotavirus season [25]. We have not seen such influence on the Polish epidemiological situation of rotavirus gastroenteritis yet, because vaccination coverage against rotavirus infections is still very low. At the beginning of vaccine availability in Poland in 2007 , only $3 \%$ of infants were vaccinated against rotavirus infection. A gradually rising trend reached the rate of 20\% in 2011 and then it started to decrease from 2012. Low vaccination coverage has a weak influence on herd immunity against rotavirus infection in the population. Therefore, in our cohort study, the rotavirus vaccine effectiveness in preventing acute gastroenteritis could be higher than in populations with high vaccination coverage. The small number of

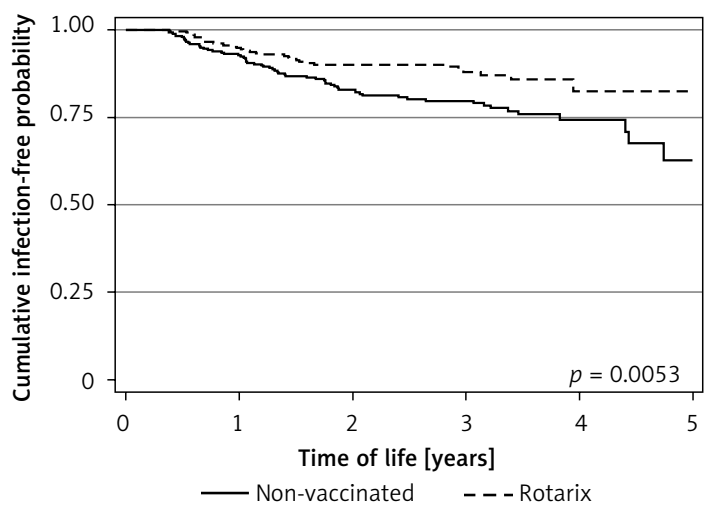

Figure 1. Kaplan-Meier curves of acute gastroenteritis incidence during the 5-year period in the vaccinated and non-vaccinated group 
Table II. Relative risk of wintertime gastrointestinal infections during the first five years of life in children vaccinated against rotaviruses

\begin{tabular}{|llll|}
\hline Variable & HR & $95 \% \mathrm{Cl}$ & $P$-value \\
\hline Univariate analysis: & & & \\
\hline Rotarix vaccination & 0.56 & $0.36-0.85$ & 0.007 \\
\hline Birth weight < 2500 g & 2.21 & $1.02-4.77$ & 0.044 \\
\hline Breast feeding $\leq 6$ months & 1.32 & $0.55-3.15$ & $\mathrm{NS}$ \\
\hline Breast feeding > 6 months & 1.10 & $0.47-2.56$ & $\mathrm{NS}$ \\
\hline Mother's education (higher or university) & 0.90 & $0.52-1.57$ & $\mathrm{NS}$ \\
\hline Father's education (higher or university) & 0.79 & $0.52-1.20$ & $\mathrm{NS}$ \\
\hline Other children in the family & 0.88 & $0.58-1.32$ & $\mathrm{NS}$ \\
\hline Age & 0.91 & $0.73-1.14$ & $\mathrm{NS}$ \\
\hline Multivariate analysis: & & & 0.008 \\
\hline $\begin{array}{l}\text { Vaccination } \\
\text { Birth weight < 2500 g }\end{array}$ & 0.56 & $0.37-0.86$ & 0.041 \\
\hline
\end{tabular}

Cox proportional hazards regression model: $\mathrm{HR}$ - hazard ratio, $\mathrm{Cl}$ - confidence interval.

Table III. Relative risk of wintertime gastrointestinal infections in children vaccinated against rotaviruses

\begin{tabular}{|lccc|}
\hline & $P$-value & HR $(95 \% \mathrm{Cl})$ & Effectiveness $(95 \% \mathrm{CI})$ \\
\hline In the first year of life & NS & $0.67(0.34-1.32)$ & $32.9(-32.2-65.9)$ \\
\hline In the first 2 years of life & 0.022 & $0.57(0.36-0.92)$ & $42.5(7.5-64.3)$ \\
\hline In the first 3 years of life & 0.012 & $0.56(0.36-0.88)$ & $43.7(11.8-64.0)$ \\
\hline In the first 4 years of life & 0.006 & $0.55(0.35-0.84)$ & $45.5(16.1-64.5)$ \\
\hline In the first 5 years of life & 0.007 & $0.56(0.36-0.85)$ & $44.3(14.8-63.5)$ \\
\hline
\end{tabular}

Cox proportional hazards regression model: $H R$ - hazard ratio, $\mathrm{Cl}$ - confidence interval.

vaccinated infants did not significantly decrease the risk of being infected by rotavirus for another population; thus the gastroenteritis incidence in the unvaccinated cohort could be higher than in a population with the effect of herd immunity. This is one reason why it is difficult to compare our results with the previous studies, because mostly they were related to populations with higher rotavirus vaccination coverage than the Polish children [26].

In the previous papers related to rotavirus vaccine effectiveness in preventing acute gastroenteritis, the analysis was conducted for hospitalized and outpatient cases separately, with the effectiveness of $47 \%$ and $15 \%$, respectively (results concerning RotaTeq) [27]. Our results calculated hospitalized and outpatient cases together revaled the effectiveness about $45 \%$. Similar effectiveness as in Poland was obtained for Rotarix in the Israeli population - 50\% in preventing acute gastroenteritis requiring a physician's visit [28]. The findings of our study cannot be compared with most of the other reports because they were mainly related to direct effectiveness of rotavirus vaccines in preventing rotavirus gastroenteritis [29-32]. In our study population, there was not a sufficient number of etiologically confirmed gastroenteritis cases, and the reliability of laboratory confirmation was rather poor. Therefore, we decided to include in our analysis the hospital admissions and outpatient visits due to all-cause acute gastroenteritis. That limitation did not allow us to determine the real vaccine effectiveness against rotavirus infections but only the indirect influence of the effectiveness on preventing allcause gastroenteritis in children during five rotavirus seasons. Despite having no data on dominant rotavirus serotypes and no reliable data on the burden of rotavirus infections in children, our findings suggest high health benefits of rotavirus vaccination in Poland.

The long period of follow-up, through five winter-spring rotavirus seasons, is a strength of our study. We revealed the vaccine effectiveness during several seasons, despite the potential changeability of dominant rotavirus serotypes in 
the relatively long period of time [9]. Furthermore, we obtained similar vaccine effectiveness not only in infants up to the $2^{\text {nd }}$ year (as in many previous studies) but also in children up to the $4^{\text {th }}$ year of life. This is the first study related to rotavirus vaccine effectiveness in an Eastern European country. We were able to include in our analysis many potentially confounding factors known to be associated with vaccine effectiveness and the increased risk of gastrointestinal infections [33, 34].

The limitation of the study is the exclusion from the analysis of infants vaccinated with RotaTeq. The small number of infants did not allow any conclusive results to be obtained with respect to this vaccine's effectiveness. On the other hand, our cohort study allowed us to reveal the high effectiveness of Rotarix in preventing acute gastroenteritis in children. This is more important information for us because more than $90 \%$ of infants vaccinated in Poland were administered this vaccine.

In conclusion, our findings show that Rotarix is highly effective in preventing acute gastroenteritis during rotavirus seasons in Polish children.

\section{Acknowledgments}

This project was funded by Jagiellonian University Medical College (grant no. K/ZDS/002417).

\section{Conflict of interest}

The authors declare no conflict of interest.

\section{References}

1. Soriano-Gabarró M, Mrukowicz J, Vesikari T, Verstraeten T. Burden of rotavirus disease in European Union countries. Pediatr Infect Dis I 2006; 25 (1 Suppl.): S7-11.

2. Nitch-Osuch A, Kuchar E, Kosmala A, Życińska K, Wardyn K. Nosocomical rotavirus gastroenterocolitis in a large tertiary paediatric hospital in Warsaw, 20062010. Arch Med Sci 2013; 3: 493-8.

3. Vesikari T, Van Damme P, Giaquinto C, et al. European Society for Paediatric Infectious Diseases/European Society for Paediatric Gastroenterology, Hepatology, and Nutrition evidence-based recommendations for rotavirus vaccination in Europe: executive summary. J Pediatr Gastroenterol Nutr 2008; 46: 615-8.

4. Ruiz-Palacios GM, Pérez-Schael I, Velázquez FR, et al. Safety and efficacy of an attenuated vaccine against severe rotavirus gastroenteritis. N Engl J Med 2006; 354: 11-22.

5. Linhares AC, Velázquez FR, Pérez-Schael I, et al. Efficacy and safety of an oral live attenuated human rotavirus vaccine against rotavirus gastroenteritis during the first 2 years of life in Latin American infants: a randomised, double-blind, placebo-controlled phase III study. Lancet 2008; 371: 1181-9.

6. Vesikari T, Karvonen A, Prymula R, et al. Efficacy of human rotavirus vaccine against rotavirus gastroenteritis during the first 2 years of life in European infants: randomised, double-blind controlled study. Lancet 2007; 370: 1757-63.
7. Bernstein DI, Sack DA, Rothstein E, et al. Efficacy of live, attenuated, human rotavirus vaccine 89-12 in infants: a randomised placebo-controlled trial. Lancet 1999; 354: 287-90.

8. Santos N, Hoshino Y. Global distribution of rotavirus serotypes/genotypes and its implication for the development and implementation of an effective rotavirus vaccine. Rev Med Virol 2005; 15: 29-56.

9. Zeller M, Rahman M, Heylen E, et al. Rotavirus incidence and genotype distribution before and after national rotavirus vaccine introduction in Belgium. Vaccine 2010; 28: 7507-13.

10. Phua KB, Lim FS, Lau YL, et al. Safety and efficacy of human rotavirus vaccine during the first 2 years of life in Asian infants: randomised, double-blind, controlled study. Vaccine 2009; 27: 5936-41.

11. Vesikari T, Matson DO, Dennehy P, et al. Safety and efficacy of a pentavalent human-bovine (WC3) reassortant rotavirus vaccine. N Engl J Med 2006; 354: 23-33.

12. Vesikari T, Itzler R, Karvonen A, et al. RotaTeq, a pentavalent rotavirus vaccine: efficacy and safety among infants in Europe. Vaccine 2009; 28: 345-51.

13. Madhi SA, Cunliffe NA, Steele D, et al. Effect of human rotavirus vaccine on severe diarrhea in African infants. N Engl J Med 2010; 362: 289-98.

14. Armah GE, Sow SO, Breiman RF, et al. Efficacy of pentavalent rotavirus vaccine against severe rotavirus gastroenteritis in infants in developing countries in sub-Saharan Africa: a randomised, double-blind, placebo-controlled trial. Lancet 2010; 376: 606-14.

15. Zaman K, Dang DA, Victor JC, et al. Efficacy of pentavalent rotavirus vaccine against severe rotavirus gastroenteritis in infants in developing countries in Asia: a randomised, double-blind, placebo-controlled trial. Lancet 2010; 376: 615-23.

16. Mrukowicz JZ, Krobicka B, Duplaga M, et al. Epidemiology and impact of rotavirus diarrhoea in Poland. Acta Paediatr Suppl 1999; 88: 53-60.

17. National Institute of Public Health - National Institute of Hygiene. "Infectious diseases and poisonings in Poland in 2008", Warsaw 2009; 26-29 [http://www.pzh. gov.pl/oldpage/epimeld/2008/Ch_2008.pdf].

18. National Institute of Public Health - National Institute of Hygiene. "Infectious diseases and poisonings in Poland in 2010", Warsaw 2011; 29-31 [http://www.pzh. gov.pl/oldpage/epimeld/2010/Ch_2010.pdf].

19. National Institute of Public Health - National Institute of Hygiene. "Infectious diseases and poisonings in Poland in 2012", Warsaw 2013; 30-34 [http://www.pzh. gov.pl/oldpage/epimeld/2012/Ch_2012.pdf].

20. Matthijnssens J, Ciarlet $M$, Heiman E, et al. Full genome-based classification of rotaviruses reveals a common origin between human Wa-Like and porcine rotavirus strains and human DS-1-like and bovine rotavirus strains. J Virol 2008; 82: 3204-19.

21. Glass RI, Parashar UD, Bresee JS, et al. Rotavirus vaccines: current prospects and future challenges. Lancet 2006; 368: 323-32.

22. National Institute of Public Health - National Institute of Hygiene. Reports on cases of infectious diseases and poisonings in Poland (biweekly, quarterly, semi-annualy, annualy) 2008-2012. [http://www.pzh.gov.pl/oldpage/ epimeld/index_p.html\#01].

23. Pang XL, Koskenniemi E, Joensuu J, Vesikari T. Effect of rhesus rotavirus vaccine on enteric adenovirus-associated diarrhea in children. J Pediatr Gastroenterol Nutr 1999; 29: 366-9. 
24. Patton JT. Rotavirus diversity and evolution in the post-vaccine world. Discov Med 2012; 13: 85-97.

25. Centers for Disease Control and Prevention (CDC). Delayed onset and diminished magnitude of rotavirus activity - United States, November 2007-May 2008. Morb Mortal Wkly Rep 2008; 57: 697-700.

26. O’Ryan M, Lucero Y, Linhares AC. Rotarix ${ }^{\circledR}$ : vaccine performance 6 years postlicensure. Expert Rev Vaccines 2011; 10: 1645-59.

27. Cortes J, Curns A, Tate J, et al. Impact and effectiveness of rotavirus vaccine on diarrhea-associated healthcare utilization in US children. 47th Annual Meeting of the Infections Diseases Society of America (IDSA). 29 October-1 November 2009; Philadelphia, PA USA.

28. Muhsen K, Chodick G, Goren S, Shalev V, Cohen D. The uptake of rotavirus vaccine and its effectiveness in preventing acute gastroenteritis in the community. Vaccine 2010; 29: 91-4.

29. Bellido-Blasco JB, Sabater-Vidal S, Salvador-Ribera Mdel $M$, et al. Rotavirus vaccination effectiveness: a casecase study in the EDICS project, Castellón (Spain). Vaccine 2012; 30: 7536-40.

30. Vesikari T. Rotavirus vaccination: a concise review. Clin Microbiol Infect 2012; 18 (Suppl. 5): 57-63.

31. Castilla J, Beristain X, Martínez-Artola V, et al. Effectiveness of rotavirus vaccines in preventing cases and hospitalizations due to rotavirus gastroenteritis in Navarre, Spain. Vaccine 2012; 30: 539-43.

32. Braeckman T, Van Herck K, Meyer N, et al. Effectiveness of rotavirus vaccination in prevention of hospital admissions for rotavirus gastroenteritis among young children in Belgium: case-control study. BMJ 2012; 345: e4752.

33. Vesikari T, Prymula R, Schuster V, et al. Efficacy and immunogenicity of live-attenuated human rotavirus vaccine in breast-fed and formula-fed European infants. Pediatr Infect Dis J 2012; 31: 509-13.

34. Adlhoch C, Hoehne M, Littmann M, et al. Rotavirus vaccine effectiveness and case-control study on risk factors for breakthrough infections in Germany, 2010-2011. Pediatr Infect Dis J 2013; 32: e82-9. 